\title{
HPLC Fingerprint Analysis with in - vitro Antimalarial Activity and Bioassay Guided Fractionation of Two Organic Extract from Ageratum conyzoides Leaves
}

\author{
A. Mulula ${ }^{1 *}$, G. Mbiye ${ }^{2}$ \\ ${ }^{1}$ Department of Chemistry, Faculty of Sciences, University of Kinshasa, P. O Box 190, Kinshasa XI, Democratic Republic of Congo \\ ${ }^{2}$ Faculty of Letters, Cairo University, Egypt
}

\begin{abstract}
We investigated the antimalarial activities of fractions from cyclohexane and dichloromethane extracts of Ageratum conyzoides Leaves. These extracts were fractionated using preparative - TLC and six fractions were obtained for each extract. The antimalarial activity of these fractions was evaluated against Plasmodium falciparum. Fractions 4 (F4) and 5 (F5) from dichloromethane extract showed the best antimalarial activities against the parasite with $I C_{50}$ values of 0.25 and $0.30 \mu g / m L$, respectively. The HPLC profile of these most active fractions were developed and showed two and three major peaks respectively for fraction 4 (F4) and 5 (F5). Preliminary phytochemical screening revealed the presence of alkaloids, steroids and terpenoids in the fraction 4, whereas only steroids and terpenoids were found in the fraction 5 (F5). Thus, these fractions could be considered as the prospective fractions to be developed as antimalarial drugs.
\end{abstract}

Keywords: Ageratum conyzoides, antimalarial activity, fractionation, HPLC, Thin Layer Chromatography (TLC)

\section{Introduction}

Malaria is a preventable and curable disease, yet it remains a devastating tropical disease, with a high infection and mortality statistics. It is the most prevalent parasitic disease and the most common cause of hospital visitation in Democratic Republic of the Congo [1]. Globally, there are approximately 214 million malaria cases in 97 countries with ongoing malaria transmission and $80 \%$ of these cases were reported in the Sub - Saharan Africa. The disease caused approximately 438, 000 deaths, $90 \%$ of which were in Sub - Saharan Africa, and $78 \%$ of these deaths occur in children under 5 years [2]. The main challenge to the effective management of diagnosed malaria cases is the resistance of the plasmodium parasite to commonly used antimalarial drugs, which results in the non - resolution of symptoms and in treatment failure [3, 4].

Cases of resistance are currently extending to the artemisinin combination therapy with report of resistance to artemisinin drugs coming from Thailand, Vietnam, and Cambodia [2, 5 7]. Furthermore, no new class of antimalarial drug has beenintroduced in clinical practice in the last 10years $[8,9]$. This strongly supports the need for further research into new products that could complement the existing antimalarial, bearing in mind that it takes minimum of 10 years to develop a drug from discovery stage to completion of clinical trials [10]. The development of safe and effective anti - malarial preparations by simple procedures from locally grown medicinal plants, may offer new and complimentary drugs for malaria control, especially in remote geographical locations and in rural areas where modern antimalaria drugs are not readily available and malaria mortality is higher [11].
Ageratum conyzoides (A. conyzoides) (Family: Asteraceae) is one of such plants with folkloric reputation as antimalarial agent. It is an annual herbaceous plant widely distributed in the tropics as an herbal weed. Extracts of the plant have been used in traditional medicines as remedies against wounds and burn, microbial infections, arthrosis, headache, inflammation dyspnea, pain, asthma, spasms, gynaecological diseases, leprosy and other skin diseases [12]. In Africa, $A$. conyzoidesis also traditionally used totreat fever, rheumatism, headache, malaria, pneumonia, wounds, burns and colic [13]. An earlier pharmacology study of the plant showed significant positive antimalarial activity in rats [14]. The leaves extracts and essential oil from Ageratum conyzoides have been found to have antimicrobial activities in vitro $[15,16]$

This research was designed to evaluate the thein - vitro antimalarial activity of fractions obtained from cyclohexane and dichloromethane extract of A. conyzoides leaves and their phytochemical screening.

\section{Materials and Methods}

\subsection{Plant Collection and Authentication}

The leaves of Ageratum conyzoides were collected from their natural habitats in Mont - ngafula Township, Kinshasa city, Democratic Republic of the Congo (DRC).

The collected plant leaves were authenticated by INERA (Institute National d' Etudes et RecherchesAgronomiques) Herbarium at Faculty of Science, University of Kinshasa. These leaves were steam - dried at $30^{\circ} \mathrm{C}$ for 24 hours then milled into powdered used to prepare extracts.

Volume 10 Issue 10, October 2021 www.ijsr.net 


\subsection{Plant Extraction and fractionation.}

\subsubsection{Crude extract}

The crude extraction was performed by maceration of $300 \mathrm{~g}$ dried leaves powder in $1000 \mathrm{~mL}$ of methanol - water (7: 3) at room temperature for $48 \mathrm{~h}$. The solution was filtered and the filtrate named crude extract was stored and used for preparing organic extracts.

\subsubsection{Organic extracts}

The crude extract filtrate was extracted successively by two solvents (cyclohexane, and dichloromethane) using a separating funnel. At the end of separation, all phases were evaporated under reduced pressure using a Rotary evaporator for obtaining Cyclohexane and Dichloromethane extracts which were stored in a refrigerator $\left(4^{\circ} \mathrm{C}\right)$ until required for all assays.

\subsection{Fractionation of cyclohexane and dichloromethane extract}

Analytical - Thin Layer Chromatography (TLC), preparative - TLC and qualitative - HPLC were used according to the methods described in the literature [17, 18].

\subsubsection{Analytical Thin Layer Chromatography (TLC)}

The portions of cyclohexane or dichloromethane extracts were dissolved in dichloromethane solvent for obtaining the test solution.

A strip of the precoated silica gel was cut out. Using a capillary pipette, a spot of the test solution was applied on the plate about $1.5 \mathrm{~cm}$ from the edge. It was dried using hot air dryer. The strip was lowered into a small chromatographic jar containing the solvent system. The jar was covered with a glass lid. The solvent was allowed to ascend until the solvent front was about $3 / 4$ of the length of the strip. The strip was removed and dried by a hot air dryer and viewed under UV lamp at 365 and $254 \mathrm{~nm}$ to identify the fluorescing spot. The fluorescent spot was marked and then sprayed with iodine and sulfuric vanillin spray in order to brown and purplish - pink marks respectively. The purplish - pink marks became black after heating the trip at $120^{\circ} \mathrm{C}$.

The colour reaction was recorded and the relative Retention factor (Rf) value was calculated based on the formula described by Stahl [17]:

$$
R f=\frac{\text { Distance traveled by the streak from the starting point }}{\text { Distance traveled by the solvent from the starting point to the solvent front. }}
$$

\subsubsection{Preparative Thin Layer Chromatography (TLC)} Preparative TLC was performed on $20 \times 20 \mathrm{~mm}$ glass plates precoated with $1.5 \mathrm{~mm}$ layers of silica gel GF254 (Kieselgel 60 G Merck).

A $7 \mathrm{~mm}$ margin on both sides of the plate was marked and the area from the edge of the plate to the mark was not streaked. In the application of fractions, dropping pipettes $(10 \kappa)$ were used to apply the various pooled fractions on the activated plates. Drops of the pooled fractions were applied in line to form a straight line streak or band. Each streak was dried before another one was superimposed on it.

The streaked plates were run in a chromatographic chamber containing $40 \mathrm{~mL}$ Cyclohexane - dichloromethane - ethyl acetate, 1: 4: 1 and ethyl acetate - cyclohexane, 1: 1 as the eluting solvent respectively for cyclohexane and dichloromethane extracts.

Each plate containing a single pooled fraction was viewed under ultra - violet lamp at 254 and $366 \mathrm{~nm}$ in a dark room. The marked separated zones were scrapped off the glass plates with a spatula onto a clean sheet of paper. The scrapings were transferred into centrifuge tubes containing 5 $\mathrm{ml}$ of absolute methanol. The content of the centrifuge tube was shaken manually for 10 mins. The eluent was separated from the adsorbent by centrifuging at $2500 \mathrm{rpm}$ for $10 \mathrm{mins}$. This process was repeated until it was satisfactory that all the eluent was collected as much as possible. The collected eluent in methanol was evaporated to dryness using a hot air oven at the temperature of $40^{\circ} \mathrm{C}$ in order to obtain different fractions which were used for phytochemical screening, and antimalarial test.

2.3.3. HPLC Finger - Printing of most active fractions
The most active fractions of dichloromethane extract ( 4 and 5) were finger - printed by HPLC (Agilent Technology). The concentration of extracts was $10 \mathrm{mg} / \mathrm{mL}$. HPLC optimum conditions: Injection volume: $10 \square \mathrm{L}$, Detection wavelength: $280 \mathrm{~nm}$, Mobile phase: Methanol: Trifluoroacetic acid (0.05\%) (Gradient condition), Temperature: $25^{\circ} \mathrm{C}$, Pump pressure: 400bar, Flow rate: $20 \mu \mathrm{L} / \mathrm{min}$, and running time: $30 \mathrm{~min}$

\subsection{Phytochemical Tests}

The cyclohexane and dichloromethane fractions were subjected to phytochemical investigation for identification of alkaloids, flavonoids, anthocyanins, tannins, quinones, saponins, steroids, and terpenoids using standard procedures [19 - 22].

\subsection{Antimalarial Activity}

\subsubsection{Parasites}

Fresh clinical isolates of Plasmodium falciparum were obtained from Hospital center of Kindele (Mont - ngafula township), in Kinshasa, Democratic Republic of the Congo (DRC). Rapid diagnostic test was realized for Plasmodium species identification. The parasite density was determined by counting the number of infected erythrocytes. From donor, $4 \mathrm{~mL}$ of venous blood was collected in a tube coated with EDTA (Greiner Labortechnik). Samples with monoinfection due to Plasmodium falciparum and a parasite density between $1 \%$ and $2 \%$ were used for the in vitro antimalarial tests. 


\section{International Journal of Science and Research (IJSR) \\ SJIF (2020): 7.803}

The parasites were cultivated and maintained continuously in human erythrocytes according to previously described methods [23].

\subsubsection{In Vitro Antimalarial Assay Procedure.}

The antimalarial activity of each fraction was evaluated against the strain of $P$. falciparum using the method described in the literature [24]. A stock solution of $100 \mu \mathrm{g} / \mathrm{mL}$ of fractions was prepared in methanol $(\mathrm{MeOH})$. These were further diluted in complete medium to attain the final concentrations of $50 \mu \mathrm{g} / \mathrm{mL}$.

The stock solutions were prepared on the assay day. Basic quinine was used as the standard reference drug (positive control).

Extracts was serially diluted twofold in complete medium (RPMI) up to $0.195 \mu \mathrm{g} / \mathrm{mL}$ using a flat bottomed, 96 - well microtitre plate.

Unparasitised erythrocyte was added to column 1 (blank) which had no drugs, while parasitized red blood cells were added to columns $2-12$. The plate was incubated at $37^{\circ} \mathrm{C}$ for 48 hours. After incubation, $50 \mu \mathrm{L}$ of each well were placed on the glass slide and air - dried for 24 hours. GIEMSA was added and microscope lecture was realized. The concentration of any substance that inhibited $50 \%$ of the parasite growth $\left(\mathrm{IC}_{50}\right)$ was determined in triplicata.

\section{Results and Discussion}

\subsection{Fractionation of cyclohexane and dichloromethane extract}

The results of analytical - TLC test of cyclohexane and dichloromethane extracts and characteristics of the spots are resumed in table 1 .

TLC profiling of the extracts gives an impressive result that directing towards the presence of number of phytochemicals. Various phytochemicals gives different $\mathrm{Rf}$ values in different solvent system. This variation in $\mathrm{Rf}$ values of the phytochemicals provides a very important clue in understanding of their polarity and also helps in selection of appropriate solvent system for separation of compounds by preparative - TLC.

Compound showing high $\mathrm{Rf}$ value in less polar solvent system have low polarity and with less $\mathrm{Rf}$ value have high polarity. Mixture of solvents with variable polarity in different ratio can be used for separation of pure compound from plant extract. The selection of appropriate solvent system for a particular plant extracts can only be achieved by analyzing the $\mathrm{Rf}$ values of compounds in different solvent system.

In the present study, each extract gave 6 spots which were viewed under UV lamp (366 and $254 \mathrm{~nm}$ ), iodine and sulfuric vanillin spray. These spots indicated the presence of six major groups of phytochemical constituents in each extracts.

Cyclohexane - dichloromethane - ethyl acetate, 1: 4: 1 and ethyl acetate - cyclohexane, 1: 1 were found to be best eluting solvents for the separation of constituents from cyclohexane and dichloromethane extracts, respectively.

The results of fractionation of cyclohexane and dichloromethane extracts, the yield and the characteristics of the fractions are resumed in table 2.

Fractionation of cyclohexane and dichloromethane extracts using Preparative - TLC produced six (6) fractions for each extract which were viewed under UV lamp at $366 \mathrm{~nm}$.

Based on this table, the yield values of fractions obtained ranged from 8.09 to $33.09 \%$ and 10.02 to $21.09 \%$ for cyclohexane and dichloromethane extracts, respectively.

For fractions from cyclohexane extract, Fraction number 6 (F6) had the highest yield (33.09\%) followed by fractions 1 , $5,2,3$ and 4 . Whereas, for the fractions from dichloromethane; Fraction number 4 (F4) had the highest yield (21.09\%) followed by fractions 5, 1, 2, 3 and 6 .

Table 1: Characteristics of the spots from cyclohexane and dichloromethane extracts

\begin{tabular}{|c|c|c|c|c|c|c|c|}
\hline Extracts & & $\mathrm{R}_{\mathrm{f}}$ & Visible light & UV: 254nm & UV: 366nm & Iodine spray & Sulfuric vanillin spray \\
\hline \multirow{5}{*}{ Cyclohexane } & Spot 1 & 0 & Brown & Brown & - & Brown & - \\
\cline { 2 - 8 } & Spot 2 & 0.11 & - & Brown & - & - & - \\
\cline { 2 - 8 } & Spot 3 & 0.16 & - & - & Light blue & - & - \\
\cline { 2 - 8 } & Spot 4 & 0.27 & - & Brown & - & - & Black \\
\cline { 2 - 8 } & Spot 5 & 0.52 & - & Brown & - & - & Black \\
\cline { 2 - 8 } & Spot 6 & 0.63 & - & Brown & - & Brown & Black \\
\hline \multirow{5}{*}{ Dichlorométhane } & & & & & & & Black \\
\cline { 2 - 8 } & Spot 1 & 0 & Brown & Brown & - & Brown & - \\
\cline { 2 - 8 } & Spot 2 & 0.16 & - & - & Light blue & - & - \\
\cline { 2 - 8 } & Spot 3 & 0.28 & - & Brown & - & Brown & - \\
\cline { 2 - 8 } & Spot 4 & 0.40 & - & - & Light blue & - & Black \\
\cline { 2 - 8 } & Spot 5 & 0.80 & - & - & - & - & Black \\
\cline { 2 - 8 } & Spot 6 & 0.9 & - & - & - & - & \\
\hline
\end{tabular}

\subsection{Phytochemicals tests of different fractions}

Results of phytochemical screening of different fractions from cyclohexane and dichloromethane extracts of Ageratum conyzoïdesleaves were summarized in Table 3.
This table revealed for cyclohexane fractions, the presence of terpenoids in all fractions with a large amount in F1 and F2.

\section{Volume 10 Issue 10, October 2021}




\section{International Journal of Science and Research (IJSR) ISSN: 2319-7064 \\ SJIF (2020): 7.803}

The absence of tannins and anthocyanins in all fractions except F6 and F1, respectively. The alkaloids were found only in the fractions 3 and 4.

However, for dichloromethane fractions the presence alkaloids, tannins, steroids, and terpenoids were revealed in the fractions. The presence of terpenoids in all fractions with a large amount in F6, F2 and F3.

\subsection{Antimalarial Activity of fractions}

The results of in - vitro antimalarial activity of of different fractions from cyclohexane and dichloromethane extracts of Ageratum conyzoïdesleaves are summarized in Table 4.

This table showed that only the fractions F1, F2, and F5 from cyclohexane extract were classified as active antimalarial activity whereas fractions F3, F4 and F6 were classified as inactive. Fraction 5 (F5) was the most active fraction with $\mathrm{IC}_{50}$ value of $5.17 \mu \mathrm{g} / \mathrm{mL}$. This fraction contains only steroids and terpenoids. Thus, this antimalarial action may be attributed to these compounds.

In additional, fractions F2, F3, F4 and F5 from dichloromethane extract were classified as very active antimalarial activity whereas fractions F1 and F6 were classified as less active and inactive, respectively. Fraction 4 (F4), which had only alkaloids, steroids and terpenoids, was found to be the most active antimalarial fraction $\left(\mathrm{IC}_{50}=0.25\right.$ $\mu \mathrm{g} / \mathrm{mL})$ following by fraction $5\left(\mathrm{IC}_{50}=0.30 \mu \mathrm{g} / \mathrm{mL}\right)$ which had only steroids and terpenoids. Thus, this antimalarial activity may be attributed to the combination these three secondary metabolites.

Both fractions (F4 and F5) showed also best antimalarial activity than Quinine $\left(\mathrm{IC}_{50}=1.35 \mu \mathrm{g} / \mathrm{mL}\right)$ which was use as positive control. Therefore, these fractions are the prospective fractions to be developed as antimalarial agents.

According to the literature, extracts that have very active antimalarial activity with $\mathrm{IC}_{50}$ values $\leq 5 \mu \mathrm{g} / \mathrm{mL}$, were classified into active, less active and inactive when $\mathrm{IC}_{50}$ values were $5-15,15-30$ and $>30 \mu \mathrm{g} / \mathrm{mL}$, respectively [25].

The HPLC profile of the most active fractions 4 and 5 showed three and two major peaks, respectively (Figure 1 and 2).

These results are similar to phytochemical screening which revealed the presence of two compounds (alkaloids, terpenoids and steroids) in the fraction $4(\mathrm{~F} 4)$ whereas two compounds (terpenoids and steroids) in the fraction 5 (F5).

By comparing chromatograms of both fractions, the first group of peaks which appears from 9 to 15 minutes could represent terpenoids and steroids, whereas the single peak which appears from 26 to 29.7 minutes could represent alkaloids.

Table 2: Yields and Characteristics of the fractions from cyclohexane and dichloromethane extracts

\begin{tabular}{|c|c|c|c|c|c|c|c|}
\hline Extracts & Fractions & $R_{f}$ & Visible light & UV: $366 \mathrm{~nm}$ & Weight (g) & Yield $(\%)$ & Colour \\
\hline \multirow{7}{*}{ Cyclohexane } & F1 & 0.13 & Dark green & Violet & 0.32 & 23.53 & Reddish \\
\hline & $\mathrm{F} 2$ & 0.29 & Darkyellow & Darkmallow & 0.15 & 11.03 & Dark green \\
\hline & F3 & 0.43 & Brown & Blue & 0.13 & 9.56 & Light Green \\
\hline & F4 & 0.54 & Dark green & Light mallow & 0.11 & 8.09 & Light Green \\
\hline & F5 & 0.68 & Dark green & Purple & 0.20 & 14.71 & Yellowish \\
\hline & F6 & 0.93 & Brown & Black & 0.45 & 33.09 & Dark green \\
\hline & & & & & Tot: 1.36 & & \\
\hline \multirow{7}{*}{ Dichloromethane } & F1 & 0.29 & Dark Brown & - & 0.91 & 18.99 & Reddish \\
\hline & $\mathrm{F} 2$ & 0.38 & Dark Brown & - & 0.89 & 18.58 & Yellowish \\
\hline & F3 & 0.54 & light Brown & - & 0.55 & 11.48 & Green \\
\hline & $\mathrm{F} 4$ & 0.59 & light Brown & - & 1.01 & 21.09 & Light Green \\
\hline & F5 & 0.71 & Green & - & 0.95 & 19.83 & Light Green \\
\hline & F6 & 0.97 & Yellow & - & 0.48 & 10.02 & light Brown \\
\hline & & & & & Tot: 4.79 & & \\
\hline
\end{tabular}

Table 3: Phytochemical screening of the different fractions

\begin{tabular}{|c|c|c|c|c|c|c|}
\hline Extracts & Fractions & Alkaloids & Anthocyanins & Tannins & Steroids & Terpenoids \\
\hline \multirow{5}{*}{ Cyclohexane } & F1 & - & ++ & - & ++ & ++ \\
\cline { 2 - 7 } & F2 & - & - & - & - & + \\
\cline { 2 - 7 } & F3 & ++ & - & - & - & + \\
\cline { 2 - 7 } & F4 & + & - & - & + & + \\
\cline { 2 - 7 } & F5 & - & - & - & + & + \\
\cline { 2 - 7 } & F6 & - & - & ++ & ++ & ++ \\
\hline \multirow{5}{*}{ Dichloromethane } & & & & & & \\
\cline { 2 - 7 } & F1 & - & No tested & + & - & + \\
\cline { 2 - 7 } & F3 & - & No tested & + & - & ++ \\
\cline { 2 - 7 } & F5 & + & No tested & ++ & + & ++ \\
\cline { 2 - 7 } & F6 & - & No tested & - & + & + \\
\cline { 2 - 7 } & & + & No tested & - & + & + \\
\hline
\end{tabular}

$+++=$ abundantly present; $++=$ moderately present; $+=$ present; $-=$ absent .

Volume 10 Issue 10, October 2021 www.ijsr.net 


\section{International Journal of Science and Research (IJSR)}

ISSN: 2319-7064

SJIF (2020): 7.803

Table 4: Antimalarial activity of the different fractions

\begin{tabular}{|c|c|c|c|}
\hline Extracts & Fractions & $\mathrm{IC}_{50}(\mu \mathrm{g} / \mathrm{mL})$ & Antimalarialactivity \\
\hline \multirow{5}{*}{ Cyclohexane } & $\mathrm{F} 1$ & 10.45 & Active \\
\cline { 2 - 4 } & $\mathrm{F} 2$ & 5.20 & Active \\
\cline { 2 - 4 } & $\mathrm{F} 3$ & $>50$ & Inactive \\
\cline { 2 - 4 } & $\mathrm{F} 4$ & $>50$ & Inactive \\
\cline { 2 - 4 } & $\mathrm{F} 5$ & 5.17 & Active \\
\cline { 2 - 4 } & $\mathrm{F} 6$ & $>50$ & Inactive \\
\hline & & & \\
\hline \multirow{5}{*}{ Dichloromethane } & $\mathrm{F} 1$ & 30 & Less Active \\
\cline { 2 - 4 } & $\mathrm{F} 2$ & 1.15 & Very Active \\
\cline { 2 - 4 } & $\mathrm{F} 3$ & 0.75 & Very active \\
\cline { 2 - 4 } & $\mathrm{F} 4$ & 0.25 & Very active \\
\cline { 2 - 4 } & $\mathrm{F} 5$ & 0.30 & Very active \\
\cline { 2 - 4 } & $\mathrm{F} 6$ & $>50$ & Inactive \\
\hline & Quinine & 1.38 & Very Active \\
\hline
\end{tabular}

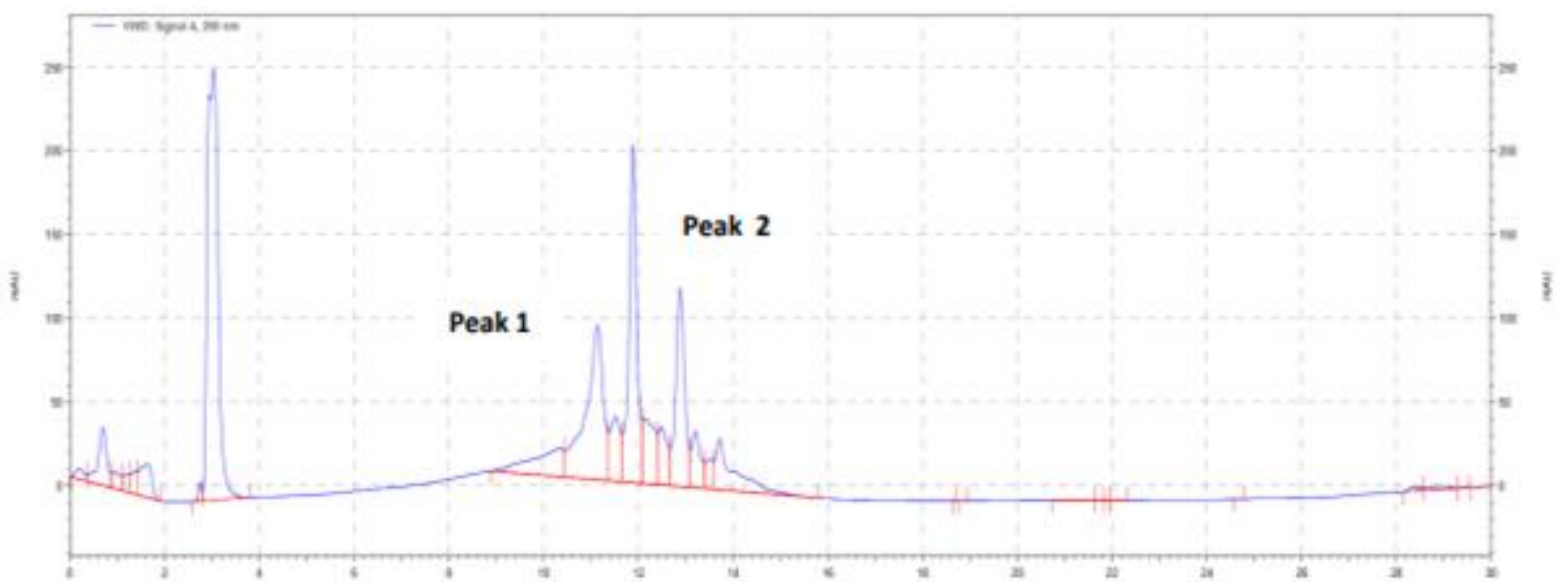

Figure 1: HPLC profiles of fraction 5 at $280 \mathrm{~nm}$.

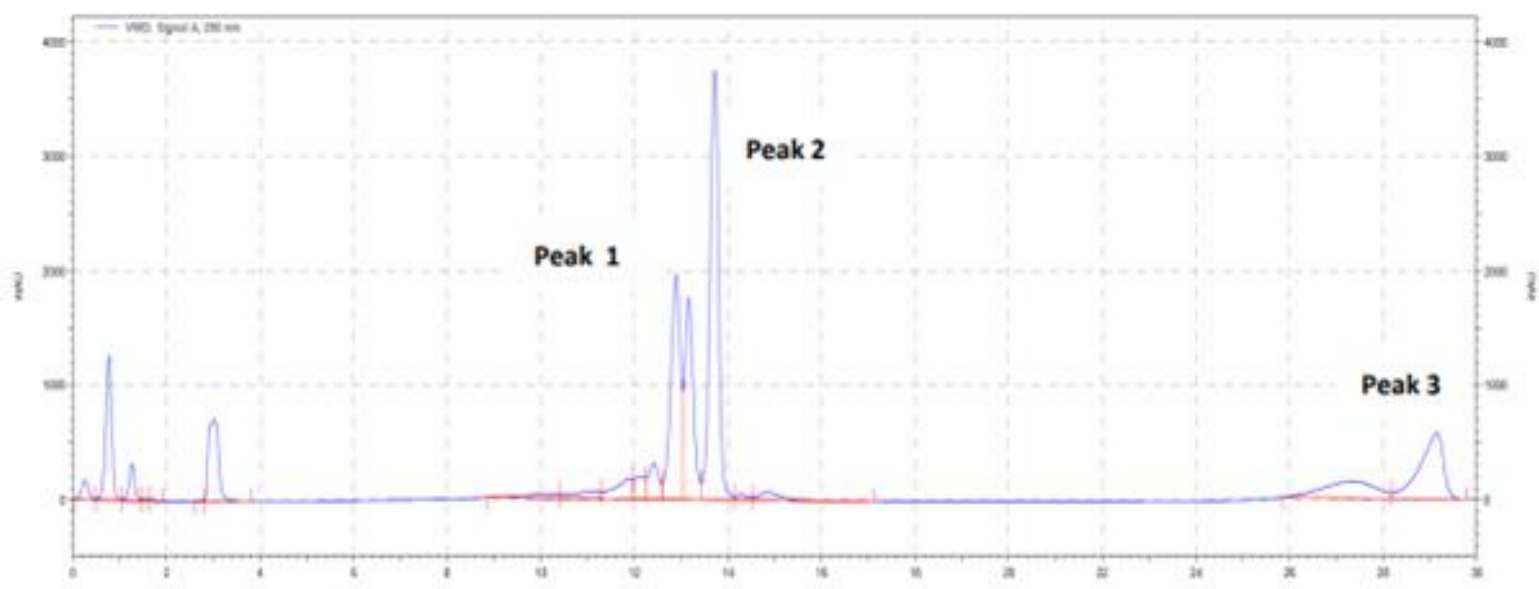

Figure 2: HPLC profiles of fraction 4 at $280 \mathrm{~nm}$.

\section{Conclusions}

In the present study, we evaluated the in - vitro antimalarial activity of fractions from cyclohexane and dichloromethane extracts of Ageratum conyzoides Leaves. Results revealed that the fractions 4 (F4) and 5 (F5) from dichloromethane extract showed the best antimalarial activities against the parasite with $\mathrm{IC}_{50}$ values of 0.25 and $0.30 \mu \mathrm{g} / \mathrm{mL}$, respectively. The HPLC profile of these most active fractions were developed and showed three and two major peaks respectively for fraction 4 (F4) and 5 (F5). Preliminary phytochemical screening revealed the presence of alkaloids, steroids and terpenoids in the fraction 4 whereas only steroids and terpenoids were found in the fraction 5 (F5). According to these results, these fractions are the prospective fractions to be developed as antimalarial agents. Therefore, it is necessary to explore preparative HPLC of these active in order to isolate, identify and characterize the active pure compounds, which can serve as useful leads for antimalarial drug discovery and development.

\section{Volume 10 Issue 10, October 2021 www.ijsr.net}




\section{Conflicts of Interest}

The authors declare that no competing interests exist regarding the publication of this paper.

\section{References}

[1] World Health Organization (WHO). World Malaria Report. Geneva: World Health Organization; 2016. p.1 $-24$.

[2] World Health Organization (WHO). World Malaria Report. Geneva: World Health Organization; 2015. p. 10 - 16.

[3] Turschner S, Efferth T. Drug resistance in Plasmodium: Natural products in the fight against malaria. Mini Rev. Med. Chem.2009; 9: 206 - 2124.

[4] Wells TN, Alonso PL, Gutteridge WE. New medicines to improve control and contribute to the eradication of malaria. Nat. Rev. Drug Discov.2009; 8: 879 - 891.

[5] Dondorp AM, Nosten F, Yi P, Das D, Phyo AP, Tarning $\mathrm{J}$, et al. Artemisinin resistance in Plasmodium falciparum malaria. N. Engl. J. Med.2009; 361: 455 67.

[6] Ashley EA, Dhorda M, Fairhurst RM, Amaratunga C, Lim $\mathrm{P}$, Suon $\mathrm{S}$, et al. Spread of artemisinin resistance in Plasmodium falciparum malaria. N. Engl. J. Med.2014; 371: 411 - 23.

[7] Amaratunga C, Lim P, Suon S, Sreng S, Mao S, Sopha $\mathrm{C}$, et al. Dihydroartemisinin - piperaquine resistance in Plasmodium falciparum malaria in Cambodia: A multisite prospective cohort study. LancetInfect. Dis. 2016; 16: 357 - 365.

[8] Newman DJ, Cragg GM. Natural products as sources of new drugs over the last 25 years. J. Nat. Prod.2007; 70: 461 - 477.

[9] Kaur K, Jain M, Kaur T, Jain R. Antimalarials from nature. Bioorg. Med. Chem.2009; 17: 3229 - 3256.

[10] Oliveira AB, Dolabela MF, Braga FC, Jácome RL, Varotti FP, Póvoa MM. Plant - derived antimalarial agents: New leads and efficient phythomedicines. Part I. Alkaloids. An Acad Bras Cienc.2009; 81: 715 - 740.

[11] Bodeker G, Willcox M. New research initiative on plant - based antimalarials. Lancet.2000; 355: 761.

[12] Kamboj A, Saluja AK. Ageratum conyzoidesL: a review on its phytochemical and pharmacological profile. Int. J. Green Pharm.2008; 2: 59 - 68.

[13] Oladejo OW, Imosemi IO, Osuagwu FC, Oyedele OO, Oluwadara OO, Ekpo OE. A comparative study of the wound healing properties of honey and Ageratum conyzoides. Afr. J. Med. Sc.2003; 32: 193 - 196.

[14] Ukwe CV, Epueke EA, Ekwunife OI, Okoye TC, Akudor GC, Ubaka CM. Antimalarial activity of aqueous extract an fractions of leaves of Ageratum conyzoïdesin mice infected with Plasmodiumberghei. Int. J. Pharm. Sc.2010; 2: 33 - 38.

[15] Osho A, Adetunji T. Antimicrobial activity of essential oil of Ageratum conyzoides L. Asian J. Sc. and Tech.2011; 2: 001 - 005

[16] Mitra PK. Antibacterial activity of an isolated compound (Ac - 1) from the leaves of Ageratum conyzoides Linn. J. Med. Plant. Stds. 2013; 1: 145 - 50.
[17] Ode O. J., Asuzu I. U., Ajayi I. E. Bioassay - Guided Fractionation of the Crude Methanol Extract of Cassia singueanaLeaves. J. Adv. Scient. Res.2011; 2: 81 - 86.

[18] Aniekan A., Udoidong, Bassey A., Etuk and Itoro E. Udo. Phytochemical and chromatographic analysis of chloroform extract of Marsdenialatifelia. Adv. Appl. Sci. Res., 2014, 5: 53 - 58.

[19] Agyare C., Koffuor G. A., Boamah V. E., Adu F. Mensah K. B., andAdu - Amoah L., "Antimicrobial and anti - inflammatory activities of Pterygotamacrocarpaand Cola gigantea (Sterculiaceae), "Evidence - Based Compl. Alt. Med.2012; Article ID 902394, 9 pages.

[20] Fatema N. Antioxidant and cytotoxic activities of Ageratum conyzoides stems. Int. Cur. Pharm. J.2013; 2: 33 - 37.

[21] Salawu O. A, Chindo B. A, Tijani A. Y, Adzu B. Analgesic, anti - inflammatory, antipyretic and antiplasmodial effects of the methanolic extract of Crossopteryxfebrifuga. J. Med. Plant. Res.2008; 2: 213 $-8$.

[22] Sofowora A. Medicinal Plants and Traditional Medicine in Africa. Ibadan, Nigeria: Spectrum Books Limited; 1993. p.151 - 3.

[23] Trager W. and Jensen J. B. "Human malaria parasites in continuous culture," Sc.1976; 193: 673-675.

[24] Karou D, Dicko M. H, Sanon S., Simpore J, Traore A. S. Antimalarial activity of SidaacutaBurmf (Malvaceae) and PteracarpuserinaceusPoir. (Fabaceae). J. Ethnopharmacol.2003; 89: 291 - 4.

[25] Philippe G., Angenot, P. deMol, Goffin E., Hayette M. P., M. Tits and Frederich M. In vitro screening of someStrychnos species for antiplasmodial activity. $J$. Ethnopharmacol., 2005; 97: 535 - 539.

Volume 10 Issue 10, October 2021 www.ijsr.net 